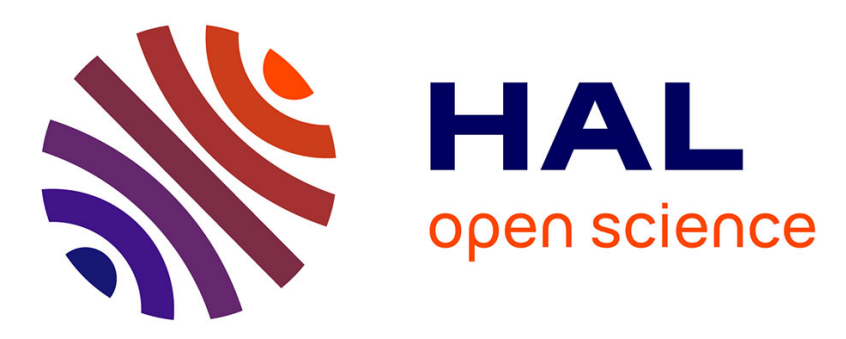

\title{
Environmental feasibility of the recycling of carbon fibers from CRFRPs by solvolysis using supercritical water
}

Marion Prinçaud, Cyril Aymonier, Anne Loppinet-Serani, Nicolas Perry, Guido Sonnemann

\section{To cite this version:}

Marion Prinçaud, Cyril Aymonier, Anne Loppinet-Serani, Nicolas Perry, Guido Sonnemann. Environmental feasibility of the recycling of carbon fibers from CRFRPs by solvolysis using supercritical water. ACS Sustainable Chemistry \& Engineering, 2014, 2 (6), pp.1498-1502. 10.1021/sc500174m . hal-01005341

\section{HAL Id: hal-01005341 \\ https://hal.science/hal-01005341}

Submitted on 9 Jul 2019

HAL is a multi-disciplinary open access archive for the deposit and dissemination of scientific research documents, whether they are published or not. The documents may come from teaching and research institutions in France or abroad, or from public or private research centers.
L'archive ouverte pluridisciplinaire HAL, est destinée au dépôt et à la diffusion de documents scientifiques de niveau recherche, publiés ou non, émanant des établissements d'enseignement et de recherche français ou étrangers, des laboratoires publics ou privés. 


\title{
Environmental Feasibility of the Recycling of Carbon Fibers from CFRPs by Solvolysis Using Supercritical Water
}

\author{
Marion Prinçaud, ${ }^{\dagger}$ Cyril Aymonier, ${ }^{\ddagger}$ Anne Loppinet-Serani, ${ }^{\ddagger}$ Nicolas Perry, ${ }^{*}$, and Guido Sonnemann ${ }^{\dagger}$ \\ ${ }^{\dagger}$ Institut des Sciences Moléculaires Bât. A12, Univ. Bordeaux, 351 cours de la Libération, 33405 Talence Cedex, France \\ ${ }^{\ddagger}$ Institut de Chimie de la Matière Condensée de Bordeaux CNRS, Univ. Bordeaux, ICMCB, UPR 904887 avenue du Dr. Albert \\ Schweitzer, 33608 Pessac Cedex, France \\ ${ }^{\S}$ Arts et Metiers ParisTech Bordeaux, I2M, UMR 5295, Univ. Bordeaux Esplanade des Arts et Métiers, 33405 Talence Cedex, France
}

ABSTRACT: Originally developed for high-tech applications in the aeronautic and aerospace industry, carbon/epoxy composites have been increasingly used in the automotive, leisure, and sports industries for several years. Nevertheless, the carbon reinforcement is an expensive constituent, and it has been recently shown that it is also the most environmentally impacting in a composite part manufacturing. Recycling these materials (even restricted to the reinforcement recovery) could lead to economic and environmental benefits, while satisfying legislative end-oflife requirements. The solvolysis of the matrix by water under supercritical conditions is an efficient solution to recover the carbon fiber reinforcement with mechanical properties closed to the ones of virgin fibers. This paper aims at demonstrating the environmental feasibility of the recycling of carbon fiber/thermoset matrix composites by solvolysis of the matrix in supercritical water. This demonstration is based on life cycle assessment that evaluates benefits and environmental challenges of this recycling loop.

KEYWORDS: Life cycle assessment (LCA), Supercritical water, Solvolysis, Recycling, Composites, CFRP

\section{INTRODUCTION}

Carbon fiber-reinforced plastics (CFRPs), or thermoset matrix composites, were originally developed for high-tech applications in the aeronautic and aerospace industry. For several years now, these materials have also been increasingly used in the automotive, leisure, and sports industries. In many applications in these sectors, one may seek aesthetic criterions or a simple feeling of high technology, more than highly technical properties. Thus, constituents' characteristics, and specifically reinforcements, are considered as a secondary matter and may be overemphasized regarding the function of the product. This is particularly true for nonstructural decorative parts (e.g., with a carbon look finish), for which the reinforcement is the most expensive constituent, and where glass fibers, much more less expensive, cannot be used. ${ }^{1,2}$

Today, there is no, or a limited, deposit (or very few) of carbon fibers from airplanes at the end of life because airplanes integrating such materials are only currently being built and will become waste later. In the future, the expected amount will grow year after year. Therefore, the question is this: Could carbon fibers recycled from airplanes (or from production waste from aircraft and automotive production) substitute mechanically for the majority of carbon fibers currently used in the automotive, leisure, and sports industries, considering that the recycling can be done in a cost-effective way and that the aeronautic industry will not use recycled fibers? Subsequent questions are these: How can carbon fiber-reinforced plastics be recycled? Is the recycling environmentally more sustainable than the production of virgin carbon fibers?

One of the first uses of the supercritical fluid technology in the field of recycling was applied to polymers. This technique has been developed extensively in Japan since 1995 and has been reviewed many times. ${ }^{3-5}$ Beyond plastics recycling, solvolysis in near- and supercritical fluids of thermosetting resins (phenol and epoxy resins) has attracted a great interest among the scientific community to recover materials like carbon fibers with a high added value in the past few years. To date, few studies have been carried out on the chemical recycling of these waste composites with near- and supercritical solvolysis technology. ${ }^{6-14}$ Compared to other recycling processes (mechanical recycling processes, pyrolysis, fluidized bed processes, low temperature solvolysis processes), near- and supercritical solvolysis has the huge advantage that clean carbon fibers are recovered with similar mechanical properties to pristine fibers. ${ }^{6}$ Moreover, these undamaged fibers are obtained at relatively low temperature, without using organic solvents or concentrated acids.

Near- and supercritical water and alcohols were mainly processed as solvolysis media. In fact, near- and supercritical water or alcohols play the role of solvent and reagent for the 


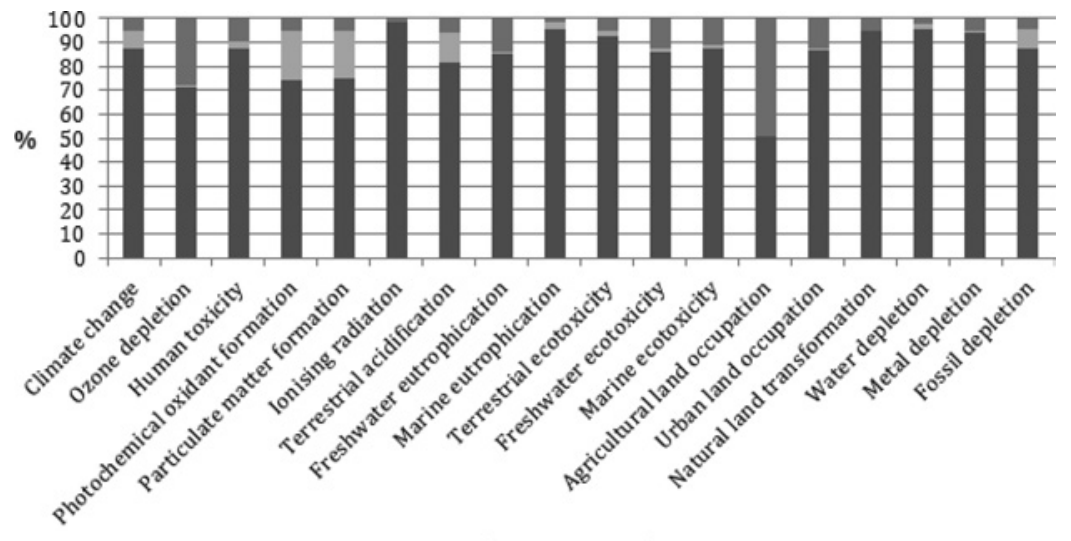

Impact categories

Méchode ReciPe MidPoint (H) $v .1 .06$

Figure 1. Environmental impacts due to the carbon reinforcement (dark gray), epoxy matrix (light gray), and injection molding process (intermediate gray), while processing a $1 \mathrm{~kg}$ carbon/epoxy composite part. The analysis is based on Duflou et al. data. ${ }^{18}$

depolymerization of condensation polymers by solvolysis into their monomers in a fast and selective way; it will be a hydrolysis reaction with water and an alcoholysis reaction with alcohols. Condensation polymers are constituted with ether, ester, or acid amide linkages, which can be broken by hydrolysis or alcoholysis. The example of polyethylene terephthalate (PET) bottle recycling is significant in term of quantity but also of development of supercritical fluid-based recycling technologies. PET can be hydrolyzed in terephthalic acid (TPA), its monomers, and ethylene glycol in sub- and supercritical water. $^{15}$ Composite plastics such as glass and carbon fiberreinforced plastics can be decomposed into monomers and fiber materials. Some years ago, the successful hydrolysis of an isolated epoxy resin in sub- and supercritical water has been already carried out. ${ }^{16}$ The solvolysis of composite materials using near- and supercritical fluids, especially water and alcohol, was recently reviewed by our group. ${ }^{6,17}$ This way is very efficient in a technological point of view, but what is about sustainability?

In this paper, the results from an initial life cycle assessment of the supercritical fluid technology applied to CFRPs recycling is proposed for the first time in order to position recycled carbon fibers in its market between virgin carbon fibers and glass fibers with regard to sustainability and cost considerations.

\section{MATERIALS AND METHODS}

Environmental Assessment. Data for CFRPs Composites Manufacture. Duflou et al. ${ }^{18}$ have some life cycle assessment (LCA)-based information on the environmental impacts due to petrochemical manufacturing of composite parts for vehicles as an alternative to steel, for lightening the vehicle, and for reducing life cycle air emissions beyond the benefits of plug-in vehicles. ${ }^{19}$ In a conventional car, the use phase has the greatest environmental impact due to high fuel consumption (directly related to the mass of the vehicle). In its lighter alternative version, it is the manufacturing phase that could become predominant. ${ }^{19}$ This is due to the carbon fiber manufacturing (see our analysis in Figure 1) based on data from Duflou et al. ${ }^{9}$ and recalculated relative to the mass of the chosen product, i.e., $1 \mathrm{~kg}$ of carbon fiber. Furthermore, the main source of impact for these carbon fibers is due to the use of fossil fuel that has an important carbon foot print. ${ }^{21}$ Hence, it might be of real interest from a sustainability point view to propose recycled fibers as a way forward to limit the environmental impacts of the composite parts of light cars.

Due to the fact that the carbon reinforcement is the most impacting constituent in a carbon/epoxy composite's elaboration process (Figure $1){ }^{18}$ recycling end-of-life composites (even restricted to the reinforcement recovery) could lead to reduce some anthropogenic impacts by decreasing the use of first-generation raw materials (mainly petroleum) for their production. Besides, it would help design engineers to balance energy efficiency and cost, by opening new opportunities for developing second-generation composites first dedicated to the manufacture of medium or low loaded parts. Lastly, recycled carbon fabric could widen the range of reinforcements on the marketplace between first-generation carbon and glass fibers.

All this has to be done in line with European directives that already force industries to improve their products' recyclability (e.g., in automotive industry ${ }^{22}$ ). However, making feasible this new recycling sector requires overcoming users' reluctances by ensuring the secondgeneration semi-product's validity from economic and environmental aspects. Therefore, we carried out a life cycle assessment (LCA) in which the resource efficiency and potential environmental challenges of the carbon/epoxy composites' recycling process are analyzed.

Life Cycle Assessment: Goal and Scope. Every stage of the life cycle of the composite part has to be modeled in the LCA, from its manufacture to its end-of-life treatment, following the usual steps defined by the ISO 14040 standards. ${ }^{23}$ These ISO standards define LCA as the following: "Compilation and evaluation of the inputs, outputs and the potential environmental impacts of a product system throughout its life cycle”. LCA is the only method that assesses the environmental impacts of a product or activity over its entire life cycle. It is a holistic approach that takes into account the extraction and treatment of raw materials, product manufacturing, transport and distribution, and product use and end-of-life. LCA is structured in the following phases: (a) goal and scope definition, (b) life cycle inventory, (c) life cycle impact assessmen, and (d) interpretation. Life cycle impact assessment assigns life cycle inventory results to impact categories like climate change and ionizing radiation; the environmental profile consisting of the indicator results for the impact categories selected provides information on the environmental issues associated with the inputs and outputs of the product system under study.

As previously mentioned, we focus on carbon/epoxy composites. The resin is an epoxy one. The carbon fibers were furnished by industry partners; therefore, we do not have any information about their precise nature. The deposit of materials to be recycled consists possibly in end-of-life aeronautic parts but, most likely to date, in composite offcuts. The composite part chosen for the LCA is assumed to be processed in Europe with Japanese carbon reinforcement. Its mass is supposed to be $1 \mathrm{~kg}$. Thus, we aim at studying the interest of recycling such materials more generally, such as the environmental feasibility of the recycling process.

Life Cycle Inventory. The following analysis is based on Duflou's data, ${ }^{18}$ which assessed the manufacturing of composite semi-structural panels in automotive industry. All of these data have been recalculated relative to the mass of the chosen product (i.e., $1 \mathrm{~kg}$ ). 
In our case study, the use phase is not taken into account. Indeed, to the best of our knowledge, the only input data that can be taken into account concern transport operations. Like so, as rather classically, the present simulation shows that this factor did not contribute much to the overall impacts (less than 5\%).

Regarding the product's end-of-life, two scenarios have been modeled: The first one consists of burying the composite part, which is what is currently done, and represents the reality for actual composites at their end-of-life. The second one consists of the recovery of the carbon reinforcement. We focus on the recycling process by solvolysis described in Figure 2). We consider (i) an

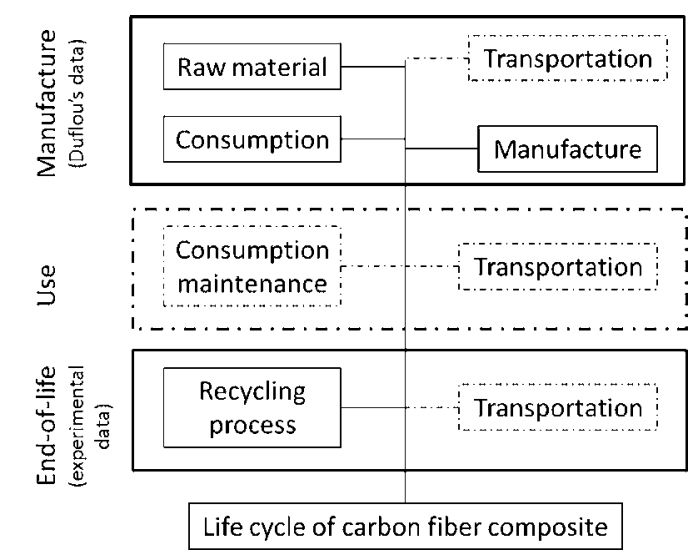

Figure 2. System boundary and life cycle stages. Dashed lines represent life cycle stages that were cut off.

aqueous solvolysis of the matrix by water under supercritical conditions (temperature around $400{ }^{\circ} \mathrm{C}$ and pressure about 25 $\mathrm{MPa}$ ) and (ii) a hydrothermal oxidation of the effluent to clear matrix components from water at the end of the solvolysis process.

This technology allows the fiber to be recovered. Therefore, it is a real (but partial) recycling and not a simple material valorization. ${ }^{6}$ Lastly, the process uses energy, water, and oxygen, and only emits water and carbon dioxide.

Lastly, the research team from the Mechanics Institute of Bordeaux has developed a prototype for packaging these second-generation fibers in an attractive form for users (i.e., designers). Data matching the remanufacturing stage have not been taken into account yet in this very first LCA. However, this energy input is assumed to be very weak compared to those involved in the first-generation reinforcement process. As a consequence, the life cycle only loops after the manufacturing of the first-generation carbon reinforcement, with no specific additional remanufacturing.

Life Cycle Assessment: Software, Database, and Method. The LCA is carried out with the SimaPro software (v.7), ${ }^{24}$ Eco Invent database (v.2), ${ }^{25}$ and ReCiPe Midpoint $(\mathrm{H})$ method. ${ }^{26}$ As previously mentioned, in the recycling stage, the avoided material is the reinforcement. In other words, the production of a new raw material with nonrenewable resources (i.e., first-generation carbon reinforcement) is avoided.

\section{RESULTS}

Recycled Carbon Fibers Obtained by Hydrolysis in Supercritical Water. The hydrolysis of the epoxy resin matrix in supercritical water $\left(p_{\mathrm{c}}=22.1 \mathrm{MPa}, T_{\mathrm{c}}=374{ }^{\circ} \mathrm{C}\right)$ has been published many times as well as the alcoholysis in supercritical alcohols (methanol, $p_{\mathrm{c}}=8.1 \mathrm{MPa}, T_{\mathrm{c}}=239.3^{\circ} \mathrm{C}$; ethanol, $p_{\mathrm{c}}=$ $6.1 \mathrm{MPa}, T_{\mathrm{c}}=240.8^{\circ} \mathrm{C}$, or still isopropanol, $p_{\mathrm{c}}=4.8 \mathrm{MPa}, T_{\mathrm{c}}=$ $235.1{ }^{\circ} \mathrm{C}$ ). For instance, Okajima et al. have studied the hydrolysis of epoxy resin of CFRPs in sub- and supercritical water in the temperature range between 300 and $450^{\circ} \mathrm{C}$ and 25 $\mathrm{MPa}$. Water in the reactor was found to inhibit the coking and enhance the decomposition of the resin compared with the case of pyrolysis. As a result, clean carbon fiber was recovered, and the resin was decomposed and removed from the carbon fiber. ${ }^{9}$ It can be pointed out that this solvolysis process is able to treat all types of composites, no matter their surface quality, geometry, size, density, etc. The only constraint is the reactor geometry.

Morin et al. have also performed the recycling of carbon fibers from carbon fiber-reinforced composites in a semicontinuous flow reactor. Experiments were carried out at a temperature around the critical temperature of water for a reaction time of about $30 \mathrm{~min}$. The process has been optimized in order to improve the solvolysis rate of the resin without the degradation of the mechanical properties of the fibers. Water or alcohols can be used as the solvolysis medium. They are different in terms of energy consumption because the critical coordinates of alcohols are generally lower than those of water. Therefore, recycling of CFRPs using an alcoholysis process could require less energy, but the hydrolysis process is safer and greener. In this study, water was used as solvent for the recycling of carbon fibers from CFRPs. The epoxy resin was completely decomposed into lower molecular weight organic compounds. Recovered carbon fibers were characterized using thermogravimetric analysis (TGA) to determine the amount of resin removed by the process, scanning electron microscopy to observe the fibers, and single fiber tensile tests to evaluate the mechanical properties of the recycled fibers. Recycled carbon fibers from CFRPs are clean (Figure 3). All the resin was

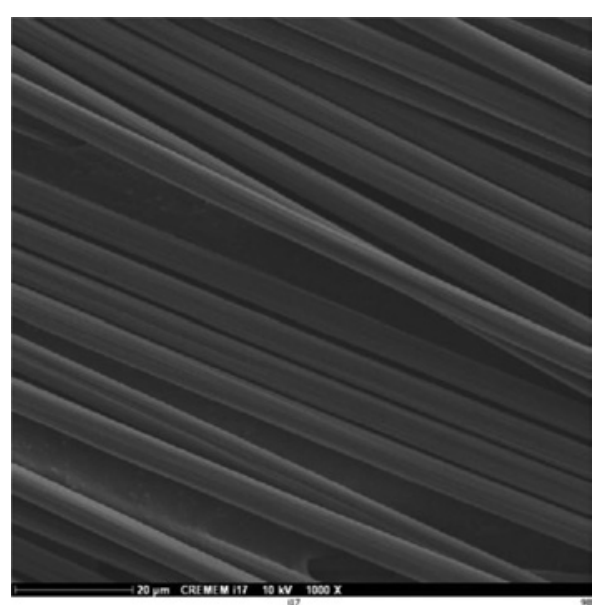

Figure 3. SEM image of recycled fibers after supercritical water treatment at $400{ }^{\circ} \mathrm{C}$ and $25 \mathrm{MPa}$ at an ICMCB laboratory.

removed according to the TGA results. Furthermore, the recycled carbon fibers present good mechanical properties; a tensile loss close to the one of virgin fibers is obtained. ${ }^{6}$ The final liquid phase is also analyzed by gas chromatography. The monomers of the initial resins have been identified.

Environmental Evaluation. The LCA of a $1 \mathrm{~kg}$ composite part that takes into account the recycling of the reinforcement clearly shows the interest of this end-of-life option. Actually, it almost offsets the whole environmental impacts of the composite manufacturing (Figure 4).

By recycling a product mainly sourced with carbon fossil fuel (Figure 1), impacts on climate change or fossil depletion can be almost completely avoided (Figure 4). For marine eutrophication, recycling allowed for a larger avoidance than the impacts of manufacturing. This is due to the use of European electricity 


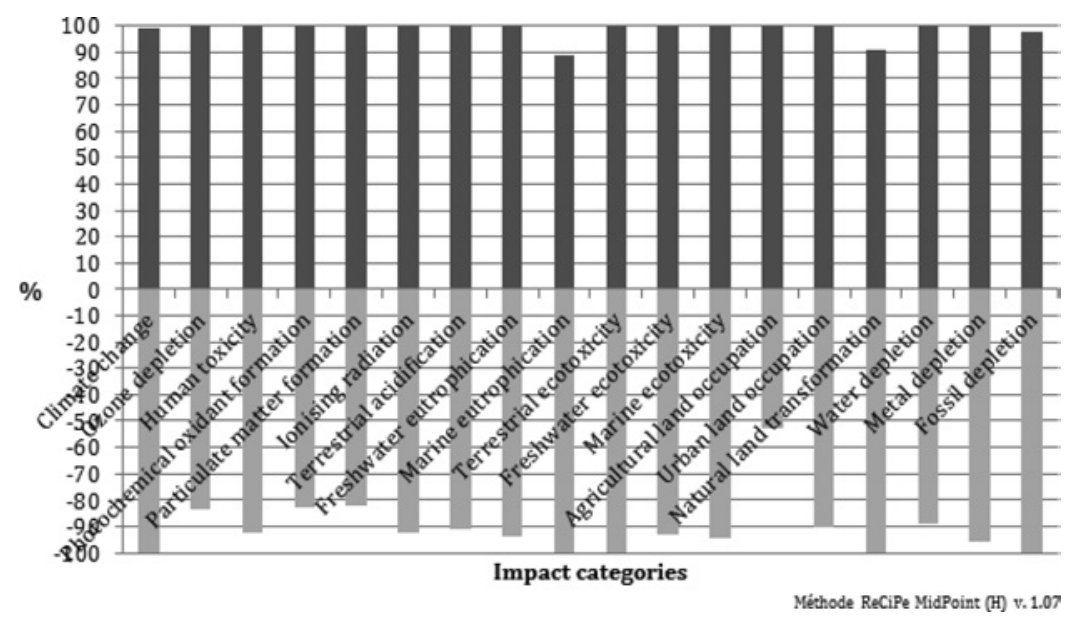

Figure 4. Life-cycle impact assessment of the landfill of a $1 \mathrm{~kg}$ carbon/epoxy composite part (dark gray) compared with the reinforcement's recycling (light gray). The analysis is based on the ReCiPe Midpoint $(\mathrm{H})$ method.

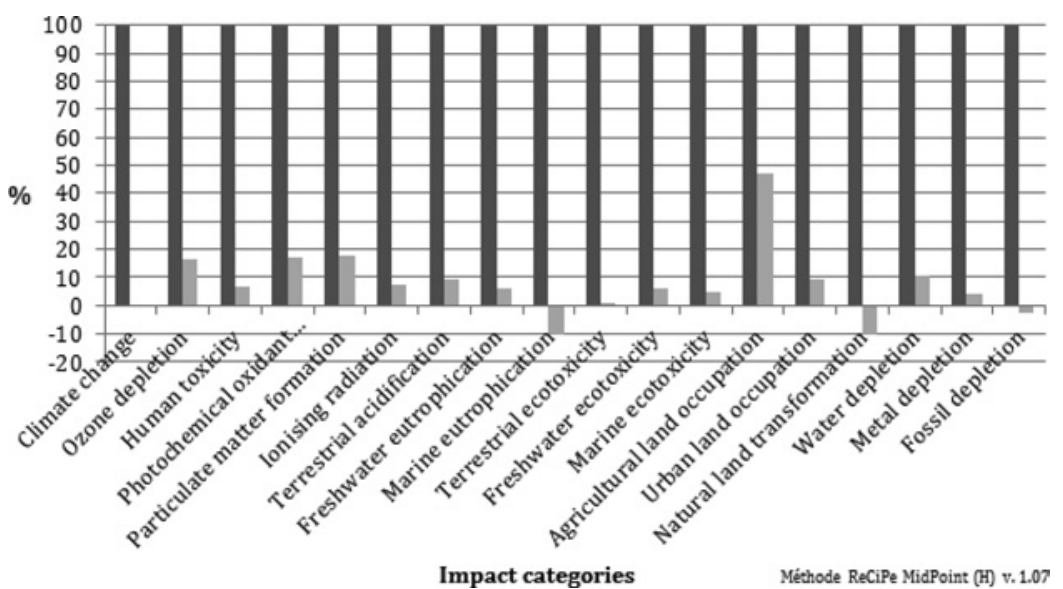

Figure 5. Comparison of the environmental impacts of a $1 \mathrm{~kg}$ composite part during its life cycle, depending on the end-of-life scenario of carbon fibers (landfill in dark gray; recycling in light gray).

for the injection molding of the matrix, while we use a French mix for recycling process (it impacts systematically onto this indicator).

When comparing the environmental impacts of a $1 \mathrm{~kg}$ composite part during its life cycle, depending on the end-oflife scenario (landfill or recycling of carbon fibers), and despite electricity consumption in the recycling process, emission of greenhouse gases may be divided by 10 (Figure 5). The environmental gain is on average about $80 \%$, according to the ReCiPe Midpoint $(\mathrm{H})$ method. For the climate change indicator, it is about $100 \%$. This is because of the use of a French electricity country mix, which is mainly sourced by nuclear energy, which is energy that has no impacts on climate change (it does impact principally on the ionizing radiation category).

Negative impacts (for eutrophication and natural land transformation indicators) do not mean that they are "good" for the environment. This only means that it is an avoided impact; to recycle, allows for avoiding some impacts due to the manufacture stage.

Economic Validation. We recently made a market study showing that there will always be relevant uses for recycled reinforcements or for semi-products based on secondgeneration fiber, whatever their mechanical characteristics are and as long as the price remains reasonable. ${ }^{26}$ The integration of recycled carbon fiber is only interesting if the mechanical performance/price ratio is higher than that of glass fiber. Therefore, in light of excellent second-generation reinforcement mechanical properties, ${ }^{27}$ this ratio should be much higher than for new carbon fibers. Thus, the feasibility of recycling will be provided if the second-generation semi-products price does not exceed $70-80 \%$ of the new ones.

\section{DISCUSSION}

In the present context, the use of carbon/epoxy composite is ever increasing. As indicted, these composites can be recycled by solvolysis, ${ }^{6}$ keeping good mechanical properties. ${ }^{27}$ Anticipating that they may soon be subjected to regulation, it is essential to show it is feasible that a composite recycling network can be set up that is both economically and environmentally favorable.

The recovery of the carbon reinforcement (which is the most environmentally impacting constituent in the composite manufacturing) by an aqueous solvolysis of the composite's matrix leads to an average gain of about $80 \%$ for all ecoindicators compared to the landfill end-of-life option.

Lastly, the remanufacturing process developed allows for obtaining a semi-product easily usable. Consequently, from an economic point of view, the mechanical performance/price ratio of the second-generation carbon fiber should be higher than that for the virgin carbon fibers or the glass reinforcement. 
The next step in the maturation of this technology is the development of a pilot scale facility for the recycling of carbon fibers from CFRPs using the supercritical fluid technology.

\section{AUTHOR INFORMATION}

\section{Corresponding Author}

*Fax: (+33)55640006994. E-mail: g.sonnemann@ism.ubordeauxl.fr.

\section{Notes}

The authors declare no competing financial interest.

\section{ACKNOWLEDGMENTS}

The authors express their thanks to the Aquitaine Regional Council for their financial support and to all the partners of the RECCO project, Innoveox, Herakles (member of Safran group), Astrium ST, and Airbus (members of AIRBUS group) and ADEME (French Environment and Energy Management Agency) for their financial support.

\section{REFERENCES}

(1) Pimenta, S.; Pinho, S. T. Recycling carbon fibre reinforced polymers for structural applications: Technology review and market outlook. Waste Manage. 2011, 31 (2), 378-392.

(2) McDonough, W.; Braungart, M.; Anastas, P. T.; Zimmerman, J. B. Applying the principles of green engineering to cradle-to-cradle design. Environ. Sci. Technol. 2003, 37 (23), 434-441.

(3) Goto, M. Chemical recycling of plastics using sub- and supercritical fluids. J. Supercrit. Fluids 2009, 47 (3), 500-507.

(4) Adschiri, T.; Lee, K. W.; Goto, M.; Takami, S. Green materials synthesis with supercritical water. Green Chem. 2011, 13 (6), 13801390.

(5) Loppinet-Serani; Aymonier, C.; Cansell, F. Supercritical water for environmental technologies. J. Chem. Technol. Biotechnol. 2010, 85 (5), $583-589$.

(6) Morin; Loppinet-Serani, A.; Cansell, F.; Aymonier, C. Near suband supercritical solvolysis of carbon fibres reinforced polymers (CFRPs) for recycling carbon fibers as a valuable resource: State of the art. J. Supercrit. Fluids 2012, 66, 232-240.

(7) Sugeta, T.; Nagaoka, S.; Otake, K.; Sako, T. Decomposition of fiber reinforced plastics using fluid at high temperature and pressure. Kobunshi Ronbunshu 2001, 58 (10), 557-563.

(8) Kamimura; Yamada, K.; Kuratani, T.; Taguchi, Y.; Tomonaga, F. Effective depolymerization waste FRPs by treatment with DMAP and supercritical alcohol. Chem. Lett. 2006, 35 (6), 586-587.

(9) Okajima; Yamada, K.; Sugeta, T.; Sako, T. Decomposition of epoxy resin and recycling of CFRP with sub- and supercritical water. Kagaku Kogaku Ronbunshu 2002, 28 (5), 553-558.

(10) Pinero-Hernanz, R.; Dodds, C.; Hyde, J.; Garcia-Serna, J.; Poliakoff, M.; Lester, E.; Cocero, M. J.; Kingman, S.; Pickering, S.; Wong, K. H. Chemical recycling of carbon fibre reinforced composites in nearcritical and supercritical water. Composites, Part A 2008, 39 (3), 454-461.

(11) Jiang, G. Z.; Pickering, S. J.; Lester, E.; Blood, P.; Warrior, N. Characterisation of carbon fibres recycled from carbon fibre/epoxy resin composites using supercritical n-propanol. Compos. Sci. Technol. 2009, 69, 192-198.

(12) Pinero-Hernanz, R.; Garcia-Serna, J.; Dodds, C.; Hyde, J.; Poliakoff, M.; Cocero, M. J.; Kingman, S.; Pickering, S.; Lester, E. Chemical recycling of carbon fibre composites using alcohols under subcritical and supercritical conditions. J. Supercrit. Fluids 2008, 46 (1), 83-92.

(13) Liu, Y.; Shan, G.; Meng, L. Recycling of carbon fibre reinforced composites using water in subcritical conditions. Mater. Sci. Eng., A 2009, 520 (1-2), 179-183.

(14) Saito, S., Ed.; Science and Technology of Supercritical Fluids; Sankyo Business, Sendai, Japan, 1996.
(15) EURECOMP Project. Recycling Thermoset Composites of the SST. 7th PCRD. May 2009-July 2012. Grant Agreement no.: 218609.

(16) Fromonteil, C.; Bardelle, P.; Cansell, F. Hydrolysis and oxidation of an epoxy resin in sub- and supercritical water. Ind. Eng. Chem. Res. 2000, 39 (4), 922-925.

(17) Loppinet-Serani, A.; Aymonier, C. Hydrolysis in Near- and Supercritical Water for Biomass Conversion and Material Recycling. In Supercritical Fluid Technology for Energy and Environmental Applications, first ed.; Anikeev, V., Fan, M., Eds.; Elsevier: Amsterdam, 2014; pp 149-154.

(18) Duflou, J. R.; De Moor, J.; Verpoest, I.; Dewulf, W. Environmental impact analysis of composite use in car manufacturing. CIRP Annals 2009, 58 (1), 9-12.

(19) Michalek, J. J.; Chester, M.; Jaramillo, P.; Samaras, C.; Shiau, C.S. N.; Lave, L. B. Valuation of plug-in vehicle life-cycle air emissions and oil displacement benefits. Proc. Natl. Acad. Sci. U.S.A 2011, 108, 16554-16558.

(20) Wittik, R.; Payet, J.; Michaud, V.; Ludwig, C.; Manson, J.-A. Assessing the life cycle costs and environmental performance of lightweight materials in automobile applications. Composites, Part A 2011, 42 (11), 1694-1709.

(21) Grice, L. N.; Nobel, C. E.; Longshore, L.; Huntley, R.; DeVierno, A. L. Life cycle carbon footprint of re-refined versus base oil that is not re-refined. ACS Sustainable Chem. Eng. 2014, 2 (2), 158164.

(22) European Parliament et European Council. Directive 2008/34/ EC of the European Parliament and of the Council of 11 March 2008 amending Directive 2002/96/EC on waste electrical and electronic equipment (WEEE), as regards the implementing powers conferred on the Commission. L 81/65, 20.3.2088. 2008.

(23) ISO 14040:2006. Environmental Management -- Life Cycle Assessment - Principles and Framework; International Organization for Standardization (ISO), 2006.

(24) Goedkoop, M. SimaPro 7 - Tutorial, v.3.2; PEé Consultants: Amersfoort, The Netherlands, 2007

(25) Frischknecht, R.; Rebitzer, G. The ecoinvent database system: A comprehensive web-based LCA database. J. Cleaner Prod. 2005, 13 (13-14), 1337-1343.

(26) ALCIMED report. Evaluation du gisement de fibres de carbone à recycler et de leur valorisation pour le consortium RECCO. 2010. Contact Dr. C. Aymonier at aymonier@icmcb-bordeaux.cnrs.fr.

(27) Goedkoop, M.; Heijungs, R.; Huijbregts, M.; De Schryver, A.; Struijs, J.; van Zelm, R. ReCiPe 2008-A Life Cycle Impact Assessment Method Which Comprises Harmonised Category Indicators at the Midpoint and the Endpoint Level. Report I: Characterisation, first ed. revised; PEé Consultants: Amersfoort, The Netherlands, July 2012.

(28) Mantaux, O.; Aymonier, C.; Antal, M. 16ème Journées Nationales Composites, Toulouse, Conference Proceedings, 2009. 